\title{
HISTOLOGIA DO APARELHO REPRODUTOR MASCULINO E MORFOMETRIA DA POPULAÇÃO CELULAR DOS FOLÍCULOSTESTICULARES DE CHROM ACRIS SPECIOSA (THUNBERG, 1824) (ORTHOPTERA: ROMALEIDAE) SUBMETIDO A TRÊS FOTOPERÍODOS
}

\section{A.V.S. Ferreira ${ }^{1}$, V. Wanderley-Teixeira ${ }^{1}$, F.A .B. Santos ${ }^{2}$, A.F.S.L. Veiga ${ }^{1}$, A.A .C. Teixeira ${ }^{1}$}

IUniversidade Federal Rural de Pernambuco, Departamento de Morfologia e Fisiologia Animal, Área de Histologia, Rua Dom Manoel de Medeiros, s/ o, CEP 52171-900, Recife, PE, Brasil. E-mail: falexx@ig.com.br

RESUMO

O objetivo da pesquisa foi descrever a histologia dos órgãos do aparelho reprodutor masculino, ereal izar a morfometria da população celular dos folícul os testiculares deC hromacris speciosa (Thunberg, 1824) (Orthoptera: Romal eidae), submetido a três fotoperíodos. Os órgãos foram anal isados através da microscopia óptica deluz. Para morfometria utilizou-se uma ocular de 10X, contendo no seu interior um retículo micrométrico square (U-OCMSQ10/ 10). Foram contad os os pontos que incidiram sobre as seguintes células: espermatogônias, espermatócitos, espermátides e espermatozóides. Os resultados mostraram que não houve influência dos fotoperíodos sobre a histologia dos órgãos bem como sobre a morfometria da população dessas células. Os testículos são revestidos por uma cápsula de tecido conjuntivo que emite septos separando cada folículo testicular. Os canais eferentes, deferentes e vesículas seminais são revestid os internamente por uma camada detecido epitelial si mples cúbico, exceto nas vesículas ondeo epitélio écolunar, apoiad o em teci do conjuntivo eexternamentetecido muscular estriado, que está ausente no canal eferente. O ducto ejaculador é constituído por epitélio do tipo estratificado colunar coberto por uma íntima na sua porção final . A baixo desse epitélio observase tecido conjuntivo. As glândulas acessórias secretam substâncias ricas em carboidratos e são constituídas por tecido epitelial, conjuntivo e muscular.

PALAVRAS-CHAVE: Gafanhoto, morfologia, reprodução, espermatogênese efotoperíodos.

\section{ABSTRACT}

HISTOLOGY OF THE MALE REPRODUCTIVE SYSTEM AND MORPHOMETRY OF CELL POPULATION OF THE TESTICULAR FOLLICLES OF CHROM A CRIS SPECIOSA (THUNBERG, 1824) (ORTHOPTERA:ROMALEIDAE) SUBMITTEDTOTHREEPHOTOPERIODS. Theobjectiveof this study was to describe the histology of the organs of the male reproductive system, and to perform the morphometry of the cell population of testicular follicles of Chromacris speciosa (Thunberg, 1824) (Orthoptera: Romaleidae), submitted to three photoperiods. The organs were analyzed by lightmicroscopy. Themorphometry wascarried outusing a 10X ocular equipped with a square micrometric reticule(U-OCM SQ10/ 10). Counting was made of the points that coincided with spermatogonia, spermatocyte, spermatid and spermcells. Theresults showed that therewas no influence of the photoperiods on the histology of the organs nor on the morphometry of the populations of these cells. The testicles are covered by a capsule of connective tissue that emits septa, separating each testicular follicle. The efferent and deferent canals as well as the seminal vesicles are covered internally by a simple cubic epithel ial layer, except in the vesicles in which theepitheliumiscol umnar, sustained in connectivetissue; externally, they arecovered by grooved muscular tissue, which is absent in the efferent canal. The ejaculator duct is constituted by an epithelium of a columnar stratified type, covered by an intima in its final part. Beneath this epithelium there is connective tissue. The accessory glands secrete substances which are rich in carbohydrates, and are constituted by epithelial, connective and muscular tissue.

KEY WORDS: Grasshopper, morphology, reproduction, spermatogenesis, photoperiods.

\footnotetext{
2UniversidadeFederal Rural dePernambuco, CPqAM-FIOCRUZ, Recife, PE, Brasil.
} 


\section{INTRODUÇÃO}

De acordo com Roberts \& Carbonell (1982) e DURANTon et al . (1987) Chromacris speciosa (Thunberg, 1824) (Orthoptera: Romaleidae) éconhecido popularmente como "gafanhoto soldado" apresentando cor verdebrilhantecommanchas amarelas easasvermeIhas alaranjadas, possuindo um tamanho médio de 20 a $30 \mathrm{~mm}$ para o macho e 35 a $50 \mathrm{~mm}$ para a fêmea.

C. speciosa éconsiderada como devastadora ocasional endêmica da A mérica do Sul tendo como hábito al imentar as solanáceas, preferindo as seguintes plantas: Cestrum parqui, C. strigillatum, C. Ioretiziana, Lycium cestoides, Sol anum agentinum eS. verbacifolium, além de compostas, leguminosas, mirtáceas egramíneas, registrando estragos em batata inglesa, arroz, cana-deaçúcar, girassol, fumo e tomateiro. Alguns autores afirmam ainda quesua presença em gramíneas éape nas casual (LARA, 1992; H ORA, 1995; GALlo et al., 2002).

O aparelho reprodutor masculino dos insetos apresenta grande diversidade quanto à morfologia. Geralmenteéconstituído por umpar detestículosdos quais partem os vasos deferentes, que desembocam na vesícula seminal edepois desta reúnem-seem um ducto único mediano, o ducto ejaculador (CHAPMAN, 1998).

É relatado paraC. speciosa quea maturidadesexual se verifica aproximadamente 10 dias após a última ecdise, ocorrendo assim a primeira cópula (TURK \& BARRERA, 1976). Na cópula, o gafanhoto macho adere aodorso dafêmeaintroduzindo-Iheapeçacopuladora na vagina, descarregando os espermatozóides (AzEVEDO \& HENNING, 1983).

Vários estudos sobre a morfologia do aparel ho reprodutor masculino e dos espermatozóides de alguns insetos têm contribuído para compreendermos a relação deafinidades entreos grupos(CRUZ-LANDIM et al., 1980; Cruz-Landim \& Moraes, 1980; Baccetti, 1987; CARCUPINo et al., 1995). Quicke et al. (1992) sugerem que em al gumas ordens de insetos as variações morfológicas nas estruturas reprodutivas dos machos são suficientes para promover um estudo filogenético e taxonômico.

Segundo UVARov (1966), as condições externas afetam a longevidade e o período de reprodução nos ortópteros. Deacordo com BЕсK (1968), o fotoperíodo éumfator externoqueinduz ou interrompeadiapausa nos insetos. Já A MORIM \& AdIs (1995) citaram que o fotoperíodo pode atuar como fator de controle (ecofator) no número deestádios ninfais degafanhotosemecossistemastropicais, mesmo sendo situados perto do equador, devido a mudanças sazonais de insolação e/ ou intensidade deluz durante o ano.

Estudando o efeito do fotoperíodo em gafanhotos adultos, TANAKA \& SODOYAma (1997) observaram que osinsetossubmetidosafotoperíodo curto realizaram posturas tardias contendo ovos inférteis. Pesquisas indicaramaindaquegafanhotosadultossubmetidos a essa condição mostram inativação das células neurossecretoras do cérebro interferindo na dinâmica hormonal, afetando a mudança de instares e o amadurecimento do aparel ho reprodutor (SAUNDERS, 1976; OKUDA \& TANAKA, 1996; ERGEN, 2001; SAUNDERset al., 2004).

Assim, diantedo exposto, apresentepesquisateve por objetivo descrever histologicamenteos órgãos do aparelho reprodutor masculino de C. speciosa (Thunberg, 1824), submetido atrêsfotoperíodos, além de realizar a morfometria da população celular dos folículos testiculares.

\section{MATERIAL E MÉTODOS}

Insetos adultos foram coletados no Município de Pombos, agreste de Pernambuco e levados para o Laboratório deEntomologia do Departamento deBiologia da UFRPE, paraa sua criação. Essesinsetosforam mantidosemgaiolasteladas, contendo recipientepara posturaealimentadoscomfolhas dejurubeba(Solanum paniculatum), trocadas a cada dois dias.

Para realização do experimento foram utilizadas 60 ninfas (30 machos e 30 fêmeas) no último estádio de desenvolvimento, sendo colocados 10 casais em gaiolas separadas e submetidos aos seguintes tratamentos: Tratamento I: $14 \mathrm{~h}$ com luz/ 10h sem luz; Tratamentoll: 10h com luz/ 14h sem luz; Tratamento III: $12 \mathrm{~h}$ com luz/ $12 \mathrm{~h}$ sem luz.

A temperaturaeumidadeforam registradas por meio de termômetro de bulbo seco e bulbo úmido (higrômetro). Foram feitas 3 aferições diárias onde as médias obtidas para a temperatura e umidade relativa foram de $30 \pm 2^{\circ} \circ$ C e $72 \pm 10 \%$, respectivamente.

Os fotoperíodos foram obtidos por meio de uma modificação da técnica preconizada por АмORIM \& ADIs (1995). Para isso, foi utilizada uma caixa de madeira, com dimensões de $180 \mathrm{~cm} \times 60 \mathrm{~cm} \times 120 \mathrm{~cm}$, dividida em 3 compartimentos, cada um contendo lâmpadas (modelo luz do dia, 40W) que forneceram cerca de 400 Lux na região ocupada pelos insetos. Dentro destacaixaforam colocadasasgaiolasteladas com os insetos, onde foram submetidos aos respectivos tratamentos. O controleda luminosidade foi realizado por meio deum timer. A limpeza das gaiolase a troca da alimentação dos insetos foram realizadas sempre que necessário e durante o dia.

Trinta dias após atingirem o estágio adul to foram coletadostestículos, canais eferentes, canais deferentes, vesículas seminais, ducto ejaculador eglândulas acessórias. Para isso os insetos foram sedados com éter etílico e dissecados sob estereomicroscópio. Os 
fragmentos dos órgãos coletados foram fixados em Boüin alcoólico empregando a metodologia descrita por MichaLANY (1990)eprocessadosparainclusãoem "paraplast". Em seguida, os blocos foram cortados em micrótomo do tipo Minot ajustado para $5 \mu \mathrm{m}$. Os cortes assimobtidosforam submetidos àstécnicas de colorações pela Hematoxilina - Eosina (H-E) (para descrição dos órgãos e morfometria), tricrômico de Mallory (para identificação de tecido conjuntivo) e P.A.S. (Ácido Periódico de Schiff) (para investigar a natureza da secreção das glândul as acessórias), empregando-se a metodologia descrita por BEH MER et al. (1976), Junqueira \& Junqueira (1983) e Michalany (1990). A análisehistológicafoi real izadautilizandose microscópio de luz e fotografados em fotomicroscópio.

Para análisemorfométrica foram utilizados cinco testículospor tratamento, ondeforamanalisadoscinco folícul os testiculares em cada repetição. Em cada folículo testicular foram contados os pontos que incidiram sobre as seguintes células: espermatogônias, espermatócitos (primários e secundários), espermátides e espermatozóides. Este procedimento foi realizado utilizando-se uma ocular de 10X, contendonoseu interior um retículo micrométrico square (U-OCMSQ10/ 10) euma objetiva de 40X(WEIBEL etal., 1966).

A análiseestatísticafoi realizada através da A nálisedeVariância(ANOVA) utilizandooProcAN OVA doSAS.

\section{RESULTADOSE DISCUSSÃO}

A nalisando os testículos, canais eferentes, canais deferentes, vesículas seminais, ducto ejaculador e glândulas acessórias de C. speciosa, submetido a três diferentesfotoperíodos, no final do último instar, por 30 dias consecutivos, observou-se que as condições fotoperiódicas testadas não influenciaram na morfologia desses órgãos.

Os testículos apresentaram-se como uma massa única e oval envolvidos por uma cápsula de tecido conjuntivo, comprovado pelacoloração dotricrômico deM allory, associado atecido gorduroso. Essetecido conjuntivo emite septos separando cada folículo testicular (Figs. 1A e 1B).

A espermatogêneseocorreda região distal para a proximal de cada folículo testicular, onde se observam nitidamente as seguintes regiões:

- Germário, constituído pelas células germinativas primordiais ou espermatogônias as quais apresentam-seunidas, com morfologia esférica, núcleo volumoso e cromatina condensada (Fig. 1C);

- Zona de crescimento, localizada após o germário, caracterizada pela presença de numerosos cistos de espermatogônias, em intensa atividade mitótica, se parados por uma delgada membrana (Fig. 1C);

- Zona de divisão e redução, constituída por espermatócitos primários e secundários. N esta região, são evidentes algumas fases da prófase I da meiosel nos espermatócitos primários (Fig. 1D);

-Zonadetransformação, constituídaporespermátides emváriosestágiosdedesenvolvimento commorfologia variando de esférica a oval, além de numerosos espermatozóides agrupados em feixes (Fig. 1E).

Os canais eferentes emergem da porção final de cada folículo testicular, sendo constituído por uma camada detecido epitelial simplescúbicoapoiadaem uma del gada camada de tecido conjuntivo (Fig. 1F).

Os canais deferentes ligam os testículos às vesículas seminais as quais são formadas por uma dilatação destes. A parede desses canais é formada por umacamadaepitelial simplescúbico, apoiadaem umadel gadacamadadetecido conjuntivo erevestida externamente por uma espessa camada de tecido muscular estriado (Fig. 2A).

A svesículas seminaistambém são revestidas por epitélio, porémesteédotiposimples colunar apoiado numadelgadacamada detecido conjuntivoeexternamenteapresentaumafinacamadadetecidomuscular estriado (Fig. 2B).

O ducto ejaculador é constituído por epitélio do tipo estratificado colunar coberto por uma íntima na sua porção final. Abaixo desse epitélio observa-se tecido conjuntivo (Figs. 2C e 2D).

Asglândulas acessóriassão revestidas, dedentro parafora, por célulasepiteliais dotiposimplescúbico eexternamentepor umacamadabastantedelicadade tecido muscular estriado associada a tecido conjuntivo. No interior desse órgão observou-se a presença de substância P.A.S. positiva (Figs. 2E e2F).

Com relação a morfometria, verificou-se que os fotoperíodos testados também não afetaram quantitativamenteapopulação celular, poisasmédias não diferiram estatisticamente $(P>0,05)$ para as espermatogônias, espermatócitos (primário e secundário), espermátideseespermatozóidesquantificados (Tabela 1).

Deacordo com TAKEDA \& SKOPIK (1997), SILVEIRA et al . (2002) eMACEDo et al. (2003) os insetos são influenciados por vários fatores ecológicos, entre eles o fotoperíodo, levando amudançascomportamentaise podendo afetar o potencial reprodutivo atuando positiva ou negativamentesobreo número deindivíduos deuma população. A lguns autores relatam ainda queinsetosmachosquando mantidosemiluminação constante tem capacidade de fertilidade reduzida, sendo para al gumas espécies, o último instar ea fase de pupa, os estágios mais sensíveis a essefator (Lum \&FLAHERTY, 1969; RIEMAN \& RUDD, 1974; CYMBOROWSKI \& Giebultowicz, 1976; Hagan \& Brady, 1981; 
Giebultowicz et al ., 1990; Bebas \& Cymborowski, 1999). Deacordocomosresultadosobtidosnãohouveinfluência dos fotoperíodos na maturidade sexual dos machos deC. speciosa, aqual segundo TuRK \& BARRERA (1976)ocorreaproximadamente10diasapósaúltima ecdise, pois a análise histológica dos órgãos e morfometria da população de células dos folículos
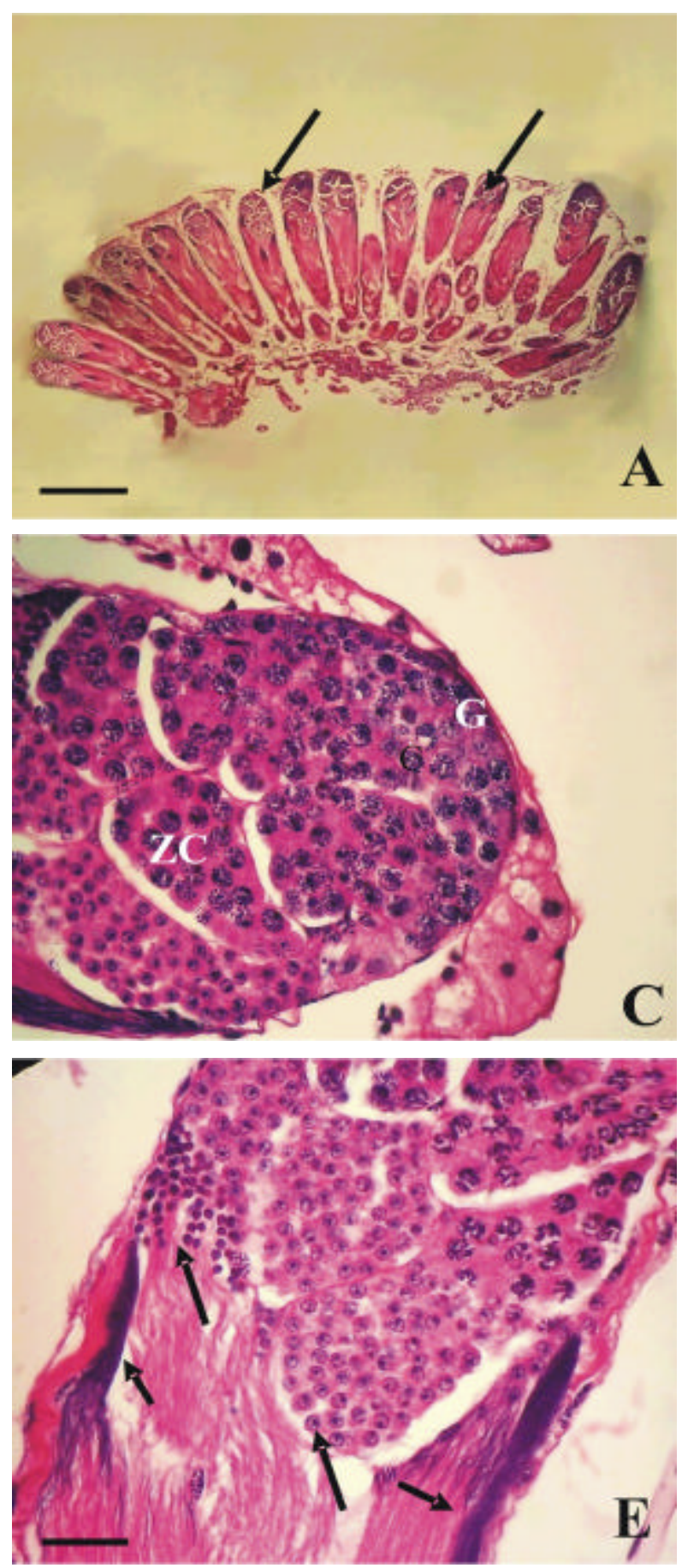

testiculares não revelaram al terações. Isto pode estar relacionado ao fato desses fotoperíodos não terem interferido na redução do ecdsônio, pois de acordo com SAUNDERS (1976), dependendo do fotoperíodo há uma inibição da liberação do hormônio protoracicotrópico impedindoaproduçãodoecdsônio pelas glândulas protorácicas.
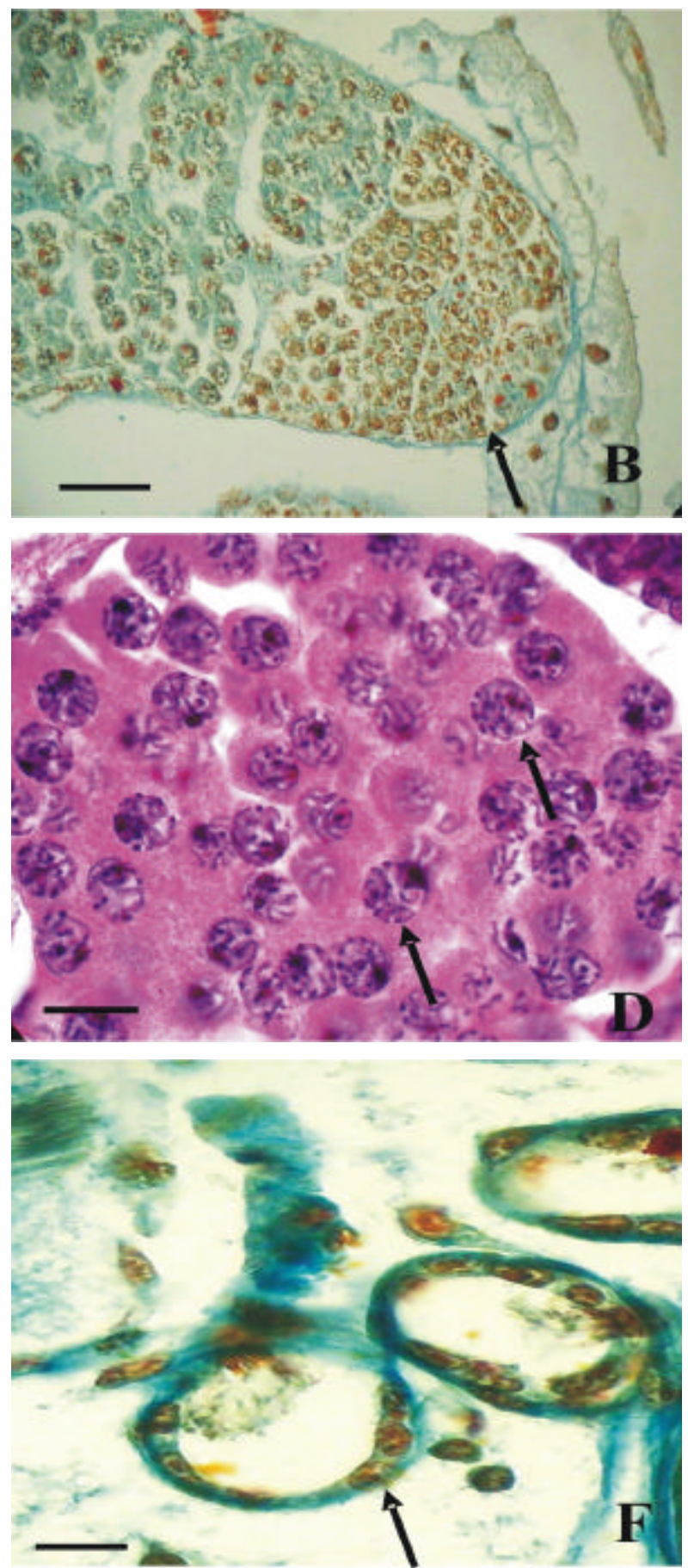

Fig. 1-Testículo deC. speciosa. A - Observar váriosfolículostesticulares(setas). H.E. Barra=250um. B-Tecido conjuntivo revestind ofolícul otesticular (seta). Tricrômico deM allory. . Barra =100um. C - Germário (G) eZonadeCrescimento (ZC)

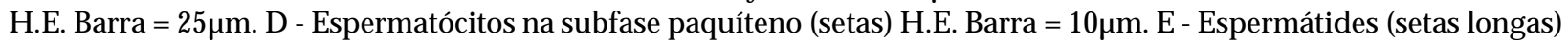

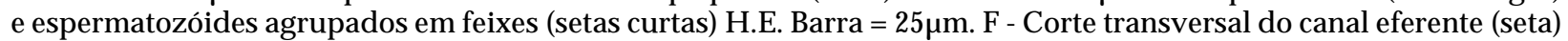
Tricrômico deMallory. Barra =25 $\mu \mathrm{m}$. 
A descrição histológica para esses órgãos, de um modo geral, está deacordo com as citações de vários autores (UVAROV, 1966; ROMOSER, 1973; BORROR et al., 1989; SNODGRASS, 1993; GHAPMAN, 1998; BuzZI \& MIYAZAKI, 1999). Com relação à presença de tecido conjuntivo envolvendo ostestículos, segundoUvarov (1966), R OM OSER (1973) eBorRor et al . (1989)estetecido
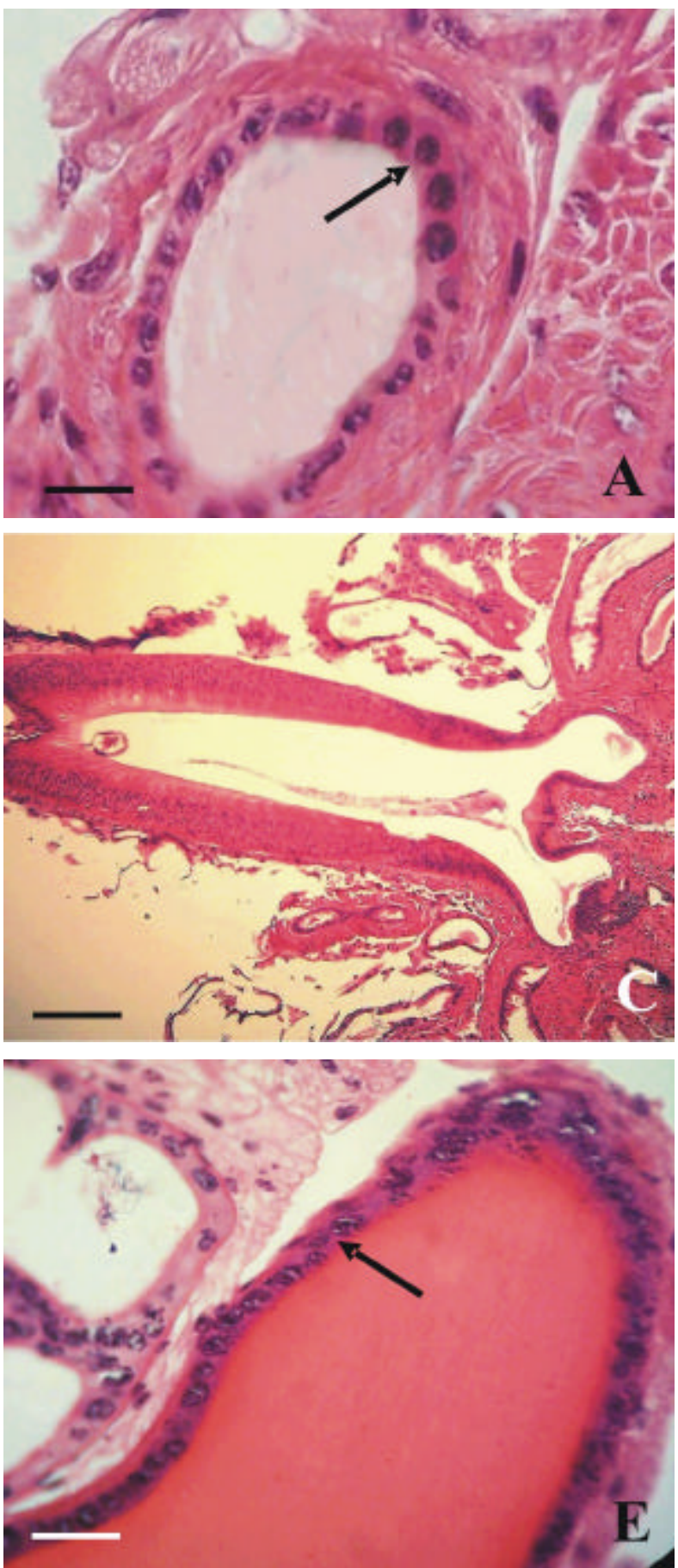

está relacionado com a membrana peritonial. No entanto, esse resultado não está de acordo com as informações de MARANHÃo (1978), que cita apenas a presença de tecido epitelial revestindo esses órgãos, formando assim a bainha epitelial. Já RICHARDS \& DAVIES (1983) descrevem queos folículostesticulares são revestidos por uma camada deepitélio associada
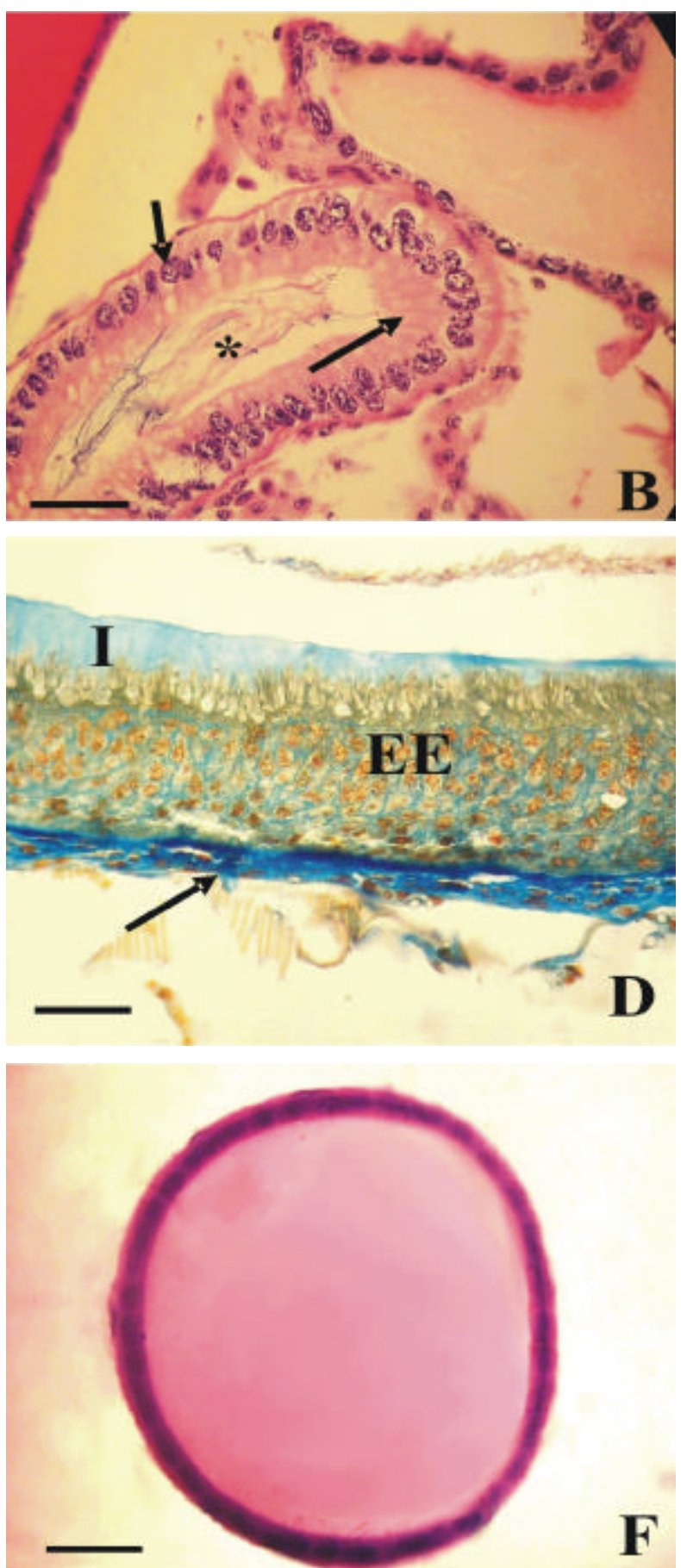

Fig. 2-A - Canal deferenterevestido internamentepor epitéliosimplescúbico (seta). H.E. Barra=25 um. B-Vesículaseminal: observar epitéliosimplescolunar (setalonga), espermatozóidesnaluz (*)edel gadacamadadetecido muscular estriado (seta curta). H.E. Barra =25 $\mu \mathrm{m}$. C - Visão geral do ducto ejaculador. H.E. Barra $=100 \mu \mathrm{m}$. D - Parede do ducto ejaculador revestido por epitélio estratificado (EE), íntima (I ) etecido conjuntivo (seta). Tricrômi cro de Mallory. Barra =25um. E -

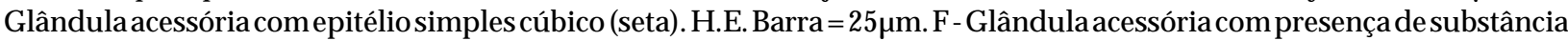
P.A.S. positiva na sualuz. P.A.S. Barra $=25 \mu \mathrm{m}$. 
Tabela 1 - Médias ( \pm erro padrão) da população celular dos folícul os testiculares de C. speciosa submetido a diferentes fotoperíodos. Temperatura $30 \pm 2^{\circ} \mathrm{C}$ e umidade relativa $72 \pm 10 \%(n=5)$.

\begin{tabular}{lllll}
\hline & \multicolumn{4}{c}{ Fotoperíodos } \\
\cline { 2 - 5 } Tipos celulares & $14 \mathrm{~L}: 10 \mathrm{E}$ & $10 \mathrm{~L}: 14 \mathrm{E}$ & $12 \mathrm{~L}: 12 \mathrm{E}$ & Estatística \\
\hline Espermatogônias & $14,60 \pm 2,01$ & $11,60 \pm 1,94$ & $9,80 \pm 0,58$ & $\mathrm{~F}_{2^{\prime} 15}=2,35 ; p=0,1381$ \\
Espermatócitos (primário e & $39,40 \pm 4,23$ & $38,80 \pm 3,43$ & $47,80 \pm 4,60$ & $\mathrm{~F}_{2^{\prime} 15}=1,50 ; p=0,2628$ \\
secundário) & & & & \\
Espermátides & $18,40 \pm 2,82$ & $15,80 \pm 2,08$ & $13,20 \pm 1,59$ & $\mathrm{~F}_{2^{\prime} 15}=1,37 ; p=0,2920$ \\
Espermatozóides & $179,60 \pm 9,79$ & $174,60 \pm 12,74$ & $184,0 \pm 15,0$ & $\mathrm{~F}_{2^{\prime} 15}=0,14 ; p=0,8731$ \\
\hline
\end{tabular}

externamente com a membrana basal e logo abaixo uma camada de tecido conjuntivo.

Os ductos genitais têm importância não só no transportedeespermatozóides, masnoprocessofinal desua maturação ena garantia desua sobrevivência notrato genital atéo momento dacópula, além dasua transferência paraa fêmea(FERnANDEZ\& C RUZ-LANDIM , 2004).

A análise histoquímica da secreção das glândulas acessórias indica a presença de carboidratos, uma vez quesecorapeloP.A.S.Esseresultadoestádeacordocom osrelatos de vários autores quecitam as glicoproténas como principal componentedasecreção dessaglândula, onde as proteínas se organizam em grânulos e os carboidratos constitui a região amorfa (GILLOT, 1995; Smid, 1998; Fernandez \& Cruz-Landim, 2004).

\section{AGRADECIMENTOS}

Ao CNPq pela concessão de bolsa ao primeiro autor, possibilitando a realização deste trabal ho.

\section{REFERÊNCIAS}

Amorim, M.A.\&J.A dis. Desenvolvimentonifal do gafanhoto neotropical semi-aquático Stenacris fissicauda fissicauda (Bruner, 1908) (Orthoptera:Acrididae) em condições controladas. A cta A mazônica, v.25, n.1-2, p.73-92. 1995.

Azevedo, A.C.P. \& Henning, G.J. Zoologia. 6.ed. Porto Alegre: Ed. Professor Gaúcho, 1983. 318p.

BACCETTI,B.M. Spermatozoaand phylogeny in orthopteroid insects, p.12-112. In BACCETTI, B.M. (Ed.). Evolutionary biology of orthopteroid insects. N ew York: John Wiley, 1987. 612p.

BEBAs, P.\& C YMBOROSWSK, B. Effect of constant light on male sterility in the cotton leafworm Spodoptera littoralis. Physiological Entomology, v.24, p.165-170, 1999.

BECK, S.D.I Insect photoperidism. N ew York:A cademicPress, 1968. p.134-207.

Behmer, O.A.; Tolosa, E.M.C.; Freitas Neto, A.G. M anual de técnicas para histologia normal e patológica. São Paulo: Edart, 1976. 115p.
BORROR, D.J.;T RIPLEHORN , C.A.;J OHNSON , N .F. A n introduction to the study of insects. 6.ed. Philadelphia: Saunders, 1989. 875p.

BuZZI,Z.J. \& M IYAZAKı, R.D. Entomologia didática. 3.ed.Curitiba: Editora da UFPR, 1999. p.71-131.

Carcupino, M.; Profili, G.; Kathirithamby, J. Mazzini, M. Spermultrastructure of $X$ enos vesparum (Rossi) and its significance in the taxonomy and phylogeny of Strepsiptera (Insecta). M emorium of M useum N atural H istory, v.166, p.291-296, 1995.

ChAPMAN, R.F. Theinsects: structureand function , London: Hodder and Stoughton, 1998. 770p.

Cruz-Landim, C.; Beig, D.; Moraes, R.L.M.S. The process of differentiation during spermatogenesis in bees (Hymenoptera, A pidae). Caryologia, v.33, p.1-15, 1980.

CRUZ-LANDIM, C. \& MoRAES, R.L.M.S. Observations on the mitochondrial complexand head differentiation during spermiogenesis of the stingless bee Melipona quadrifasciata anthidioides Lep. Cytobios, v.27, p.167$175,1980$.

Cymborowski, B. \& Giebultowicz, J.M. Effect of Photoperiod on development and fecundity in the flour moth Ephestia kuehniella. Journal of Insect Physiology, v.22, p.1213-1217, 1976.

Duranton, J.F.; Launois, M.; Luong, H.L.; Lecoq, M. Guia prático deluta contra os gafanhotos devastadores no Brasil. Roma: Fao-Cirad-Prifas, 1987. 343p.

ERGEN, G. Theeffectso precocenell on thefinestructureof corpusallattum in adult femaleA nacridiumaegyptium L. (Orthoptera: Acrididae). Turk Journal of Zoology, v.25, p.95-103, 2001.

Fernandez,F.C.\& C Ruz-Landim, C. Aspectosmorfológicos do aparel ho reprodutor masculino deA chroiagrisella (Lepidoptera: Pyralidae). Biociências, v.12, p.78-87, 2004.

Gallo, D.; Nakano, O.; Silveira Neto, S.; Carvalho, R.P.L.; Baptista, G.C.; BertI FILHO, E.; ParRa, J.R.P.; ZucChI, R.A.;A lVEs, S.B.; Vendramim,J.V.; M ARChINI,L.C.; LopeS, J.R.S.; Омото, C. Manual de entomologia agrícola. Piracicaba: Biblioteca de Ciências Agrárias “Luiz de Queiroz", 2002. 920p.

Giebultowicz, J.M.; Ridgway, L.R.; Imberski, R.B. Physiological basis for sterilizing effect of constant light in Lymantria dispar. Physiological Entomology, v.15, p.149-156, 1990.

Gillott, C. Entomology. 2.ed. New York: Plenum Press, 1995. $729 p$. 
HAGAN, D.V. \& BradY, U.E. Effecs of male photoperiod calling,pheromonelevels and ovoposition of mated fecal Trichoplusia ni. A nnals of Entomological Society of A merica, v.74, p.286-288, 1981.

HorA, M.J.L. Efeitos de diferentes regimes alimentares sobrea fecundidade e Iongevidade de Chromacris speciosa (Thumberg, 1824) (O rthoptera: Romaleidae). 1995. 37p. Monografia deGraduação (Bacharelado em Ciências Biológicas) - Universidade Federal Rural de Pernambuco, Recife, 1995.

JunqueIRA, L.C.U. \& JunqueiRA, L.M.M.S. Técnicas básicas de citologia ehistologia. São Paulo: Ed. Santos, 1983. p.50-75.

LARA, F.M. Princípios deentomologia. 3.ed. São Paulo: Ícone, 1992. 331p.

LUM, P.T.M. \& FLAHERTY, B.R. Effect of mating with males reared in continuaos light or in light-dark cycles on fecundity in Plodiainterpunctella(H ubner) (Lepidopera: Phycidae). J ournal of Stored P roduct R esearch, v.5, p.8994, 1969.

Macedo, L.P.M.; Souza, B.; Carvalho, C.F.; Escole, C.C. Influência do fotoperíodo no desenvolvimento ena reprodução de Chrysoperla externa (Hangel) (Neuroptera: Chrysopidae). N eotropical Entomology, v.32, p.91-96, 2003.

Maranhão, Z.C. Entomologia geral . 3.ed. São Paulo: Nobel, 1978. p.197-319.

MICHALANY, J.Técnica histológica em anatomia patológica. 2.ed. São Paulo: Ed. Michalany, 1990. p.126-144.

OKUDA, T. \& TANAKA, S. An Allatostatic factor and juvenile hormonesynthesisby corporaal latain locusta.j ournal of Insect Picio, v.43, p.635-641, 1996.

Quicke, D.L.J.; Ngram, S.N.; Baillie, H.S.; Gaitens, P.V. Sperm structure and ultrastructure in the Hymenoptera (Insecta). Z oologica Scripta, v.21, p.381402, 1992.

RichaRds, O.W. \& DAVIES, R.G. Entomology. 9.ed. London: Methuen, 1983. 418p.

RIEMAN , J.G. \&R UUD, R.L. Mediterranean flour moth: effects of continuous ligth on the reproductive capacity. A nnals of Entomological Society of A merica, v.67, p.857860, 1974.
Roberts, H.R. \& Carbonell, C.S. A revision of the grasshopper genera Chromacris and Xestotrachelus (Orthoptera: Romaleidae: Romaleinae). Proceeding California A cademy Science, v.43, p.43-58, 1982.

Romoser,W.S. Thescienceof entomology. New York:Macmill Publishing, 1973. 575p.

SAUnDERS, D. S. Seasonal cycles of development in: In sect clocks. New York: Pergamon Press, 1976. v.54, p.73-83.

Saunders, D.S.; LeWIS, R.D.; Warman, G.R. Photoperiodic induction of diapause: opening the black box. Physiological Entomology, v.29, p.1-15, 2004.

Silveira, F.A.; Melo, G.A.R.; AlmeidA, E.A.B. A bel has brasileiras: sistemática e identificação. Belo Horizonte: IDM Composição e Arte, 2002. 253p.

SMID, H.M. Transfer of maleacessory gland peptideto the female during mating in Leptinotarsa decemlineata. InvertebrateR eproduction and D evelopmental, v.34, p.4753, 1998.

SNODGRASS, R.E. P rinciples of insect morphology. 2.ed. London: Cornell University Press, 1993. p.567-573.

TAKEDA, M.\& SKOPIK, S.D. Photoperiodic TimeM easurement and related physiological mechanisms in insects and mites. A nnual Review of Entomology,v.42, p.323-349, 1997.

TANAKA, S. \& SADOYAMA, Y. Photoperiodic termination of diapauseinfield-collected adultsof theBombay locust, N omadacris succincta (Orthoptera: Acrididae) in southern Japan. Bulletin of Entomol ogical R esearch, v.87, p.533-539, 1997.

TuRK, S.Z. \& Barrera, M. Acridios del NOA. I. Estudios biológicos, morfométricos y aspectos ecológicos de Chromacris speciosa (Thunberg) (A crididae: Romaleinae). A cta Z oologica Lilloana, v.32, p.121-145, 1976.

Uvarov, S.B. Grasshoppersand locusts. London: Cambridge University Press, 1966. p.138-144.

Weibel, E.R.; Kistler, G.S.; Scherle, W.F. Practical stereological method for morphometrics cytology. Journal of Cell Biology, v.30, p.23-38, 1966.

Recebido em 10/ 4/ 06

A ceito em 8/ 8/ 06 